\title{
A COMUNiCAÇÃo IgNORADA: o Mundo do Rádio numa Cidade do Norte do Paraná
}

\author{
Fábio Viana Ribeiro ${ }^{1}$
}

\begin{abstract}
Resumo
0 artigo busca traçar um quadro geral da presente situação do rádio na cidade de Maringá, enfatizando as características do veículo e seu maior ou menor aproveitamento dentro dos modelos utilizados. Nesse sentido, tenta-se demonstrar que, não obstante sua enorme presença, popularidade e do fato de ser um dos únicos e mais eficazes meios de acesso ao mundo exterior por grande parte da população, o veiculo permanece sendo, tanto em função das políticas que regulam o setor quanto da forma como são administradas as emissoras, um meio praticamente desconhecido e sub-utilizado na imensa maioria dos casos.

Palavras-chave: Rádio. Comunicação de massa. Sociabilidade.
\end{abstract}

\begin{abstract}
The present article aims at delineating a general view of the current situation of the radio in Maringá city, emphasizing the characteristics of the vehicle and its major or minor utilization concerning the models used. Therefore, it can be observed that, in spite of its great presence, popularity, and the fact of being one of the unique and most efficient means of accessing abroad, considering both the policies that regulate the sector and the way the broadcasting stations are managed, it is an almost unknown and not used mean of communication in most cases.

Key words: Radio. Mass media. Sociability.

0 rádio está verdadeiramente de posse de extraordinários sonhos acordados. "Mas então, dirão alguns, a quem isso vai servir?" A todos que tiverem necessidade disso, evidentemente. "A que horas é preciso fazer essa transmissão? Para mim é preciso que seja as 8 e meia, porque me deito às 9 horas.” [...]. E se os engenheiros psíquicos do rádio forem poetas que desejam o bem do homem, a doçura do coração, a alegria de amar, a fidelidade sensual do amor, prepararão boas noites para seus ouvintes. 0
\end{abstract}

\footnotetext{
${ }^{1}$ Professor do Departamento de Ciências Sociais/UEM. Doutor em Ciências Sociais pela PUC/SP. Email: fabiovianaribeiro@pop.com.br.
} 
rádio deve anunciar a noite para as almas infelizes, para as almas pesadas: "Tratase de não mais dormir sobre a terra, trata-se de entrar no mundo noturno que você vai escolher".

Gaston Bachelard - Devaneio e Rádio.

Q uantas realidades existem? Talvez em nenhum outro campo esta dúvida explorada desde o senso-comum até os mais mirabolantes ramos da filosofia tenha conotaçã̃o tão óbvia quanto nos meios de comunicação. Não fosse a intenção auto-declarada do jornalismo de mostrar "a verdade dos acontecimentos" (pretensão que, sob a forma do "verossímil", é recorrente nos meios de comunicação em geral) talvez o problema não fosse tão curioso. Mesmo no caso de se supor a existência de umaúnica realidade ${ }^{2}$, a necessidade de se ter de escolher uma ou mais, dentre as numerosas versões produzidas pela comunicação de massa, é quase inevitável. Qualquer indivíduo que já tenhapassado pela experiência de vivenciar (seja como testemunha ou protagonista) um fato e mais tarde vê-lo reproduzido na imprensa é capaz de, perfeitamente, avaliar o que faz das duas situações (seu acontecimento e sua posterior representação) dois fatos completamente distintos. Assim, de diversas formas, o mundo dos acontecimentos "eles mesmos" é reproduzido, redefinido e reinventado através dos meios de comunicação em geral e pela imprensa em particular. Basta lembrar, num só exemplo desses diversos modos, que, do ponto de vista do noticiário internacional, nada acontece há anos em regiões tão extensas do globo quanto a Mongólia ou a Tanzânia... A realidade propriamente dita apresenta-se separada da realidade comunicacional, na qual pesam diversos recortes, seleções e adequações que buscam, entre outros objetivos, transformar acontecimentos em notícias.

Por questões que, à falta de espaço, não poderiam ser discutidas aqui, háem todo o mundo uma enorme homogeneização daquilo que se convencionou chamar de comunicação de massa. Possivelmente não seria correto falar de uma globalização do setor, uma vez que tal idéia parece (ou deveria) pressupor alguma forma de participação, envolvimento ou influência de inúmeros países e culturas na formulação de um padrão comunicacional que no momento se espalha por todos os continentes. Efetivamente tal processo não parece incluir de forma relevante (exceto como potenciais mercados consumidores) quaisquer aspectos culturais, tecnológicos ou sociais de lugares tão esquecidos ou remotos quanto o Suriname, a Islândia ou o Quênia (ou África do Sul, Índia, Brasil...). Talvez fosse mais apropriado falar, menos que de uma globalização, de um padrão particular de produção mediática, cuja origem não poderia sequer receber 0

${ }^{2}$ A esse respeito, para um ponto de vista sociológico, ver a interessante discussão feita por Alfred Schütz (1981). 
rótulo de "americanização", posto não refletir a diversidade cultural existente nos próprios EEUU, mas sim, majoritariamente, um tipo de indústria cultural que é produzida em pontos específicos das costas leste e oeste desse país. A recepção desse padrão "universal" em países periféricos parece se dar, contudo, dentro dos mais variados tipos de absorção, sendo precipitado afirmar que tais modelos são consumidos na íntegra de suas "intenções manipulatórias". Parece, nesse sentido, haver uma sempre (ou ainda) presente capacidade de retradução dos conteúdos originais produzidos pela indústria de comunicação, em que pese os elementos "imponderáveis" de culturas locais, tão particulares quanto ainda capazes de reafirmar seus valores.

Dentre os diversos meios que compõem a comunicação de massa, o rádio é 0 veículo no qual elementos locais e particulares se encontram mais presentes. Potencialmente as características que the são inerentes - regionalidade, mobilidade, oralidade, etc - contribuem para a emergência de um "aqui e agora" que dificilmente poderia vir a ser alcançado por outros veículos. Nas mesmas proporções, é também no rádio que culturas próprias e autônomas poderiam, ainda que potencialmente, emergir em meio ao quase total predomínio das grandes corporações da indústria de comunicação.

A cidade de Maringá, tão distante quanto tantos outros lugares do mundo dos grandes centros produtores da indústria cultural, possui características que, mesmo invisíveis e excluídas dos meios de comunicação, apresentam-se tão variadas e surpreendentes quanto o mundo da vida cotidiana em seus particularismos e idiossincrasias, demonstra inevitavelmente ser. Em contraste com a obrigatória necessidade de surpreender dos meios de comunicação de massa, a vida comum da cidade (e, nesse sentido, qualquer cidade do mundo...) possui como que sempre oculto entre suas esquinas, entre seus habitantes comuns e entre os pequenos dramas e alegrias de suas vidas, mais que o "comunicacionalmente esperado"; que aquilo que a velocidade e a técnica da comunicação de massa seriam incapazes de obter ou produzir. Maringá, sendo um município muito jovem (sua emancipação data de 1947) e relativamente próspero, se localiza numa região distante da capital Curitiba, próxima de Mato Grosso do Sul e do interior paulista, totalizando uma população que não chega a atingir a faixa dos 300.000 habitantes. Tais fatos, somados, lhe conferem traços de uma modernidade baseada numa história muito recente ena influência de diversos grupos e regiões, sem haver predominância de nenhuma parte. Não seria espantoso, em função disso, que suas características locais não sejam tão evidentes quanto as que marcam cidades mais antigas e só possam ser percebidas caso sua observação ultrapasse 0 terreno da superficialidadade e os eternos lugares comuns que normalmente predominam nos veículos de comunicação.

0 rádio em Maringá pode ser considerado produto e ao mesmo tempo reprodutor dos principais traços da cultura local. Certamente mais que a televisão ou a imprensa 
escrita, sua capacidade de refletir (mesmo que precária, imperfeita e muitas vezes tendenciosamente) a vida da cidade é potencialmente muito grande. A programação das emissoras, em sua quase totalidade, limita-se a reproduzir, dentro de maiores ou menores condições técnicas, formatos e modelos presentes em outras cidades; o que, em sua versão local, termina por produzir, exatamente por conta da artificialidade dessa "transferência", uma diluição daquilo que seria particular e próprio da cidade na maior parte dos modelos de programação. No caso das emissoras que operam em AM, estão presentes na programação, entre outros "clássicos": o noticiário policial, as "jornadas esportivas", a leitura do horóscopo, a "parada de sucessos”, as cartas com pseudônimo, etc. O sucesso dessas fórmulas tão infalíveis quanto "universais" reflete, mais que tudo, a grande popularidade e o potencial do veículo (e menos, talvez, um gosto "congênito" dos ouvintes por seus conteúdos). Entre as FM's, como se pode perceber pelo quadro seguinte ${ }^{3}$, esta variação é ainda menor, alterando-se apenas, com exceção das rádios Novo Tempo e CBN, 0 predomínio de uma programação musical.

\begin{tabular}{|l|c|c|}
\cline { 2 - 3 } \multicolumn{1}{c|}{} & AM & FM \\
\hline Música & $24 \mathrm{hs}$ & $111 \mathrm{hs} 30 \mathrm{~min}$ \\
\hline Jornalismo & $17 \mathrm{hs} 30 \mathrm{~min}$ & $25 \mathrm{hs} 30 \mathrm{~min}$ \\
\hline Religioso & $13 \mathrm{hs}$ & $23 \mathrm{hs}$ \\
\hline Esporte & $02 \mathrm{hs}$ & $01 \mathrm{~h}$ \\
\hline Outros $^{5}$ & $05 \mathrm{hs} 30 \mathrm{~min}$ & $03 \mathrm{~h}$ \\
\hline Total $^{6}$ & $62 \mathrm{hs}$ & $164 \mathrm{hs}$ \\
\hline
\end{tabular}

Quadro 1 - Grades de programação

Em relação ao enorme espaço que as emissoras dedicam à mera execução de música, além do conhecido argumento de que "é isto que o povo gosta", tal escolha

\footnotetext{
${ }^{3}$ Por conta de diversas peculiaridades e dificuldades encontradas na obtenção de informações junto às emissoras, a construção do quadro 1 e as grades de programação reproduzidas não se constituem em representações exatas dos conteúdos veiculados. De fato, poucas emissoras dispõem de informações sistematizadas a respeito de sua própria programação. Em muitos casos, são freqüentes as mudanças de horários, apresentadores e programas; em outros, alguns programas são definidos pela emissora como sendo de determinado gênero (jornalístico, "popular", etc), quando, efetivamente, sua audição indicou pertencerem a outro gênero. No caso da rádio Novo Tempo, por conta da quase que exclusiva matriz religiosa de seus conteúdos, os mesmo foram classificados integralmente como religiosos (e não, como no caso de outras emissoras, em gêneros "musical", "entrevistas", etc).

${ }^{4}$ A primeira, ligada ao Sistema Adventista de Comunicação, inclui em sua programação conteúdos não exclusivamente musicais; ao passo que no caso da segunda sua programação é integralmente voltada para o jornalismo.

${ }^{5} \mathrm{Na}$ categoria "outros" foram considerados: horóscopo, policial, classificados, entrevistas e variedades.

${ }^{6}$ As duas totalizações se referem ao tempo diário de transmissão das 04 emissoras que operavam em AM e 07 em FM, ao longo do segundo semestre de 2002. Foi excluído desta soma o horário compreendido entre 19:00 hs e 20:00 hs, durante o qual é feita a transmissão obrigatória de "A Voz do Brasil".
} 
baseia-se em larga medida numa concepção do veículo onde ausência de investimentos e desinteresse pela inclusão de outros conteúdos são fatores determinantes. De fato, como parte de um problema que já se inicia no processo de distribuição das concessões pelo governo federal, muitos dos proprietários de emissoras encontram na terceirizaçãa ${ }^{7}$ de horários e na idéia de "tocar música" formas muito cômodas e lucrativas de manter suas respectivas rádios em funcionamento.

Não obstante serem "estilos" de rádio muito semelhantes aos encontrados em outras muitas cidades do país, a grande popularidade do veículo parece estar relacionada, entre outros fatores, à própria "sensorialidade" que o caracteriza e distingue de outros meios de comunicação. Característica capaz de imprimir no ouvinte, como nenhum outro meio, sensações de proximidade " "confiança" . É o que se pode perceber através da grande participação dos ouvintes na programação, através de telefonemas, cartas, emails ou até mesmo pessoalmente (no caso de algumas emissoras). Seria desnecessário dizer que tal interação ocorre dentro de planos perfeitamente previstos pelas emissoras, nunca ocorrendo, por exemplo, qualquer crítica à programação, ao apresentador ou mesmo à própria rádio. Os graus dessa "interatividade" variam desde praticamente nenhuma participação - casos das rádios Antena 1 e Universitária - até quadros em que os ouvintes se fazem presentes e ao vivo nos programas; passando, é claro, pelos tradicionalíssimos pedidos de música dedicados a alguém e os infalíveis "abraços" do apresentador aos seus "amigos ouvintes". As situações mais "radicais" de interatividade ficam por conta do apresentador Benedito Cláudio Pinga Fogo de Oliveira, em seu programa que vai ao ar nas rádios Nova Ingá e Difusora ${ }^{9}$. Extremamente popular e dono de um estilo que o confunde com seus próprios ouvintes, 0 apresentador transmite com incrivel naturalidade os traços que lhe garantem enorme empatia com boa parte da população maringaense. Ainda que considerado por uma parcela de seus ouvintes como uma "pessoa importante" (sensação alimentada pelo próprio apresentador, ao citar freqüentemente seu apreço e amizade com políticos e empresários "importantes" da

\footnotetext{
${ }^{7}$ A titulo de ilustração, segundo matéria publicada na revista Maringá M9, em outubro de 1997, o horário compreendido entre 17:00 hs e 19:00 hs, na rádio Nova Ingá, era terceirizado à Igreja Católica pelo valor de R\$ $6.000,00$.

${ }^{8}$ Não por acaso, as pesquisas que buscam avaliar o grau de confiança da população nos meios de comunicação habitualmente indicam o rádio como o veículo "mais confiável". É também sintomático que inúmeros profissionais do meio, valendo-se dessa "oportunidade", sejam freqüentemente eleitos para ocupar cargos no poder legislativo. Ou, com a mesma frequiência e pelos mesmos motivos, adquiriram mais tarde suas próprias emissoras.

${ }^{9} 0$ Programa Pinga Fogo vai ao ar diariamente entre 08:00 hse 10:00 hs nas duas emissoras. Curiosamente, o próprio apresentador Pinga Fogo se apresenta apenas na rádio Nova Ingá. No caso da rádio Difusora, o Programa Pinga Fogo é apresentado por Randhal de Oliveira.
} 
cidade), a idéia de "amigo do povão" éigualmente difundida. A transcrição de um típico diálogo de seu programa ilustra bem esses traços :

(Pinga Fogo) 0 outro senhor aí o que é que é, Carlinhos?

(Repórter) ô Pinga, é um senhor que parece que caiu do telhado uns tempos atrás aí e tá precisando comprar uns remédios e tá sem condições de comprar os remédios - você caiu... é o Chico Maia que tava falando com o senhor ali, né?

(Ouvinte) Eu caí, machuquei o pescoço, usei colete quatro meses, aí ontem fui no médico, 'tava ruim, ele falou pra mim usar colete de novo e comprar esses dois remédios que é para... pro pescoço... que eu vou ter de usar colete outra vez. Que eu caí, machucou o pescoço e a coluna. Agora eu vou ter de usar esse remédio que é pra tirar a dor, que eu não consigo dormir de noite, que é de tanto doer o pescoço...

(Pinga Fogo) E você não tá conseguindo trabalhar...

Não tô podendo, que eu machuquei o pescoço, e a coluna machucada...

Tem filhos?

Não.

Então você é solteiro?

Solteiro. Virgem, se não fosse aí que tava pior ainda...

Como diz o outro, tava mais enrolado... Senão você tava mais apurado ainda...

Mais apurado...

Mas é muito caro o remédio?

Não, ele é $R \$ 29,50$.

$\mathrm{R} \$ 29,50$ ?

Isso. $\mathrm{R} \$ 29,50$.

(Carlinhos) Dois medicamentos...

(Pinga Fogo) Ahn?

(Carlinhos) Dois medicamentos ficando em $\mathrm{R} \$ 29,50$.

(Pinga Fogo) Seja o que Deus quiser, eu ajudo ele. Eu dou uma mão sim.

(Ouvinte) Tá bom.

Pode ir. Eu dou uma autorizaçãozinha e você compra ali na farmácia, tá?

Tá. Obrigado.

(Pinga Fogo) Agora são oito horas e quarenta e sete minutos. Oito e quarenta e sete.

Eu quero agradecer ao Ângelo da Farmácias Nossa, que ele agüenta minhas contas

lá. Eu pago ele todo dia 25; hoje é dia 27... Eu nem mandei ver o valor que tem lá.

Mas vou... Hoje à tarde a Terezinha já se comunica lá pra nós acertar. ${ }^{10}$

Sintomaticamente a emissora (nesse caso, a Rádio Nova Ingá) parece se confundir com a figura do próprio apresentador (em algumas vinhetas é apresentada como "a rádio

${ }^{10} 0$ trecho foi extraído do "Programa Pinga Fogo" levado ao ar em 27 de setembro de 2002.

276 - MEDIAÇÕES, LONDRINA, v. 12, N. 1, P. 271-290, JAN/JUN. 2007 
do Pinga-Fogo"), que parece imprimir sua personalidade em todos os espaços disponíveis. A análise de suas apresentações permite suspeitar que o carisma do radialista tem a ver com o fato de reunir em uma única pessoa elementos e valores de forte apelo "popular" que, normalmente, só seriam esparsamente encontrados em seis ou mais apresentadores: religiosidade, justiça, humildade, firmeza, experiência, humor, etc.

A comparação dos programas "Pinga Fogo" e "CBN Maringá" é interessante na medida em que ambos têm a mesma duração, horários muito próximos (ver quadros de programação) e, teoricamente, temáticas semelhantes (ou seja, tanto "CBN Maringá" quanto o "Programa Pinga Fogo" se auto-definem como programas jornalísticos). Apesar de certa semelhança nos tempos reservados à publicidade (ambos abaixo de 25\% do total da programação; logo dentro do limite permitido pela legislação) há uma grande diferença entre o número de notícias veiculadas em cada programa. Curiosamente, nenhum dos 10 fatos noticiados no Programa Pinga Fogo o foram no CBN Maringá (com uma única exceção); assim como nenhuma das 44 notícias veiculadas no Programa CBN Maringá (excluída a única exceção) foram noticiadas no Programa Pinga Fogo.

\begin{tabular}{|l|c|c|}
\cline { 2 - 3 } \multicolumn{1}{c|}{} & Pinga Fogo & CBN Maringá \\
\hline tempo do programa em minutos $^{11}$ & $120^{\prime}$ & $120^{\prime}$ \\
\hline tempo de publicidade em minutos & $24^{\prime}$ & $25^{\prime}$ \\
\hline número total de anúncios & 54 & 50 \\
\hline número de notícias transmitidas & 10 & 44 \\
\hline
\end{tabular}

Quadro 2 - Comparação dos programas "Pinga Fogo" e "CBN Maringá

É contudo preciso observar que, apesar de um quadro desfavorável, onde a escassez de anunciantes e a precariedade das produções não são raras, a enorme popularidade e alcance social do rádio se constituem em elementos de considerável relevância. Para grandes faixas da população, com renda familiar baixa, sem acesso à jornais, internet ou simplesmente desprovidas de meios que permitam ampliar sua educação geral, o rádio vem a ser uma das poucas alternativas de contato com o mundo exterior. Seja como meio de informação, entretenimento, auxílio (que se estende desde a mais objetiva "prestação de serviços" ao mais oportunístico "assistencialismo") ou até mesmo e tão somente como companhia e conforto. Para tanto pesam, obviamente, o baixo preço de um aparelho de rádio (tanto a aquisição de um aparelho quanto sua "manutenção"), sua mobilidade (no caso dos modelos portáteis) e sua característica de ser "falado" (o que

\footnotetext{
${ }^{11}$ A duração do Programa Pinga Fogo neste dia (27.09.02) foi, na realidade, de 100 minutos, já que os últimos 20 minutos do programa foram dedicados à reza do Terço.
} 
torna possível, ao contrário de quase todos os outros meios, que mesmo pessoas analfabetas ouçam e entendam seus conteúdos) ${ }^{12}$.

É interessante ainda observar que, em certo sentido, a sub-utilização do rádio e a precariedade de suas produções colaboram muito, paradoxalmente, na construção de seu caráter popular. Não, obviamente, por conta do argumento, muito utilizado por proprietários e diretores de programação, de ser este o modelo de rádio que "o povo gostae quer", mas em termos de que, ao contrário da calculadíssimae cara produção televisiva (onde monitoramento dos índices de audiência esofisticadas estratégias de marketing são comumente utilizadas), o caráter "intuitivo" da produção radiofônica permite uma construção menos artificial dos conteúdos e mesmo maior proximidade entre os ouvintes e o veículo. A tão recorrente queixa dos profissionais de rádio de que a parte do "bolo publicitário" reservada ao meio seria inversamente proporcional à sua importância, explicaria apenas parcialmente a subutilização do veículo, uma vez que, dentro da atual política de comunicação existente no país (em particular o modelo de distribuição das concessões e a ausência de fiscalização por parte do Ministério das Comunicações) é pouquíssimo provável que um eventual aumento de recursos viesse a se transformar em aumento da qualidade das emissoras.

A questão pouco estudada do "caráter popular" do rádio e a distinção entre, de um lado, o ponto de vista de proprietários e programadores, e de outro, a enorme inserção do mesmo entre a população necessita algum esclarecimento. Num certo grau de recorrência, o espaço ocupado pela programaçãa "popular" éde algum modo apresentada em oposição ao "universo intelectual" das elites. Assim, óbvias e antigas fórmulas são utilizadas no rádio local em nome de uma suposta contingência de fatores. As explicações clássicas que justificam tal modelo de programação vão desde os altos custos de produção (que implicam na contratação de profissionais, equipamentos, etc) até a curiosa e já mencionada crença de que os conteúdos transmitidos coincidem exatamente com o gosto do público. Diversas experiências parecem mostrar, contudo, a existência de outras alternativas. A idéia, solidamente enraizada tanto entre os profissionais do setor quanto entre o próprio público ouvinte, de que o rádio teria por finalidade "tocar música", contrasta não apenas com as características óbvias do veículo (que são, nesse sentido, desconsideradas), quanto com a bem-sucedida experiência de inúmeras rádios comunitárias ${ }^{13}$ e casos como os da Rede

\footnotetext{
${ }^{12}$ Segundo dados da PNAD, de 1992 para 1997 o percentual de domicílios com rádio subiu de 84,9\% para 90,3\%. Entre os bens pesquisados, o rádio foi, apenas depois do fogão, o mais presente nas residências.

${ }^{13}$ A Rádio São Francisco iniciou suas transmissões no dia 04 de outubro de 2002 na freqüência de 105,9 MHz. Resultado dos persistentes esforços de representantes da comunidade do Jardim Alvorada, o longo e burocrático processo que levou ao funcionamento da primeira rádio comunitária de Maringá contou com a participação de boa parte da população do bairro Jardim Alvorada. Operando com um transmissor de 25 watts (potência máxima permitida pela legislação) e atingindo um raio de cerca de um quilômetro, a emissora demonstrou, em termos práticos, a viabilidade de um outro modelo de rádio local, estimulando, inclusive, o surgimento de outras emissoras em outros bairros.
} 
CBN, rádios Gaúchae Guaíba, no Rio Grande do Sul; Jovem Pan em São Paulo, Jornal do Brasil, no Rio de Janeiro e outras que, investindo em outros modelos de programação, provaram a viabilidade e enorme potencial do veiculo. Segundo Gisela Ortriwano (1985, p. 78-81), o dimensionamento das enormes potencialidades do veículo pode ser visto através de suas principais características:

linguagem oral: 0 rádio fala e, para receber a mensagem é apenas necessário ouvir. [...] Leva uma vantagem sobre os veículos impressos, pois para receber informações não é preciso que o ouvinte seja alfabetizado. [...] Com relação à televisão, o espectador não precisa ler, apesar de, cada dia mais, os caracteres estarem sendo utilizados para prestar informações importantes, que escaparão ao analfabeto;

penetração: em termos geográficos o rádio é o mais abrangente dos meios, podendo chegar aos pontos mais remotos e ser considerado de alcance nacional. Ao mesmo tempo, pode estar nele presente o regionalismo, pois, tendo menor complexidade tecnológica, permite a existência de emissoras locais;

baixo custo: em comparação a televisão e aos veículos impressos, o aparelho receptor de rádio é o mais barato, estando sua aquisição ao alcance de uma parcela muito maior da população. [...] Por outro lado, a produção radiofônica é mais barata que a televisiva, justamente por ser menos complexa. Se levarmos em consideração 0 grande número de pessoas que recebe a mensagem radiofônica, esse custo de produçãa se dilui, tornando o rádio o meio de mais baixo custo de produção em relação ao público atingido;

imediatismo: os fatos podem ser transmitidos no instante em que ocorreram. 0 aparato técnico para a transmissão é menos complexo do que o da televisão e não existe a elaboração necessária dos impressos para que a mensagem possa ser divulgada;

sensorialidade: 0 rádio envolve 0 ouvinte, fazendo-o participar por meio da criação de um diálogo "mental" com o emissor. Ao mesmo tempo, desperta a imaginação através da emocionalidade das palavras e dos recursos de sonoplastia, permitindo que as mensagens tenham nuances individuais, de acordo com as expectativas de cada um. No caso da televisão, a decodificação das mensagens também se dá ao nível sensorial, só que a imaginação é limitada pela presença da imagem. No caso dos veículos impressos, a sensorialidade está muito mais contida, permitindo uma decodificação ao nível racional, sem envolvimentos emocionais criados pela presença da voz;

autonomia: 0 rádio, livre de fios e tomadas - graças ao transistor - deixou de ser um meio de recepção coletiva e tornou-se individualizado [...]. Essa característica faz com que 0 emissor possa falar com toda a sua audiência como se estivesse falando para cada um em particular, dirigindo-se àquele ouvinte especifico. A mensagem oral se presta muito bem para a comunicação "intimista". É como se o 
rádio estivesse "contando" para cada um em particular. Ao mesmo tempo, a atividade "ouvir" não exclui a possibilidade de desenvolver outras tarefas, como ler, dirigir, trabalhar, etc.

Seria desnecessário dizer que a imensa maioria das emissoras ignora boa parte de tais características, que conferem ao rádio um caráter tão peculiar e rico em recursos. Nesse sentido, o veículo permanece sendo, mais de um século após sua invenção, um meio extremamente moderno, bastando para isso lembrar seu imediatismo, adaptabilidade, autonomia, etc; traços que terminam por constituí-lo num dos meios que melhor correspondem às rápidas transformações e características da sociedade contemporânea.

Das onze emissoras de rádio que operam em Maringá, quatro transmitem em AM (Atalaia, Cultura, Difusora e Nova Ingá) e sete em FM (Antena 1, CBN, Cultura, Jovem Pan, Maringá FM, Novo Tempo e Universitária). Num primeiro grupo as rádios Antena 1, Cultura, Jovem Pan, e Maringá FM representam o clássico formato FM musical, distinguindo-se entre si em função do gênero musical e respectivo público-alvo. Indo desde o padrão "música ambiente" da Rádio Antena 1 (cujo grande diferencial consiste em oferecer, em uma hora, 53 minutos de música com apenas sete de intervalos comerciais) até o frenético modelo Jovem Pan. As respectivas grades de programação podem ilustrar parcialmente este quadro ${ }^{14}$ :

\begin{tabular}{|l|l|l|}
\hline 06:00 às $08: 00$ & Jornal da Manhã & Jornalismo \\
\hline 08:00 às 10:00 & Só as Melhores & Musical \\
\hline 10:00 às 12:00 & Programação Local & Musical \\
\hline 12:00 às 14:00 & Pânico & Musical \\
\hline 14:00 às 15:00 & Planeta DJ & Musical \\
\hline 15:00 às 17:00 & Só as Melhores & Musical \\
\hline 16:00 às 18:00 & Programação Local & Musical \\
\hline 18:00 às 19:00 & Seqüência Máxima & Musical \\
\hline 20:00 às 22:00 & Só as melhores & Musical \\
\hline 22:00 às $06: 00$ & Madrugada & Musical \\
\hline
\end{tabular}

Quadro 3 - Rádio Jovem Pan - FM 101,3 MHz

Fonte: site da emissora.

\footnotetext{
${ }^{14}$ A rádio Antena 1 (FM 97,9) não possui programação local, recebendo seus conteúdos por meio de sistema automatizado gerado por sua matriz. Nem o site nem a representação da emissora em Maringá indicaram a existência de uma programação "convencional", dividida em blocos, temáticas, apresentadores, etc. 0 acompanhamento de seus horários permitiu concluir que a programação da "número 01 em música" se resume a transmitir música 24 horas por dia (com intervalos comerciais, hora certa e rápidos "fatos noticiosos").
} 


\begin{tabular}{|l|l|l|}
\hline 07:00 às $11: 00$ & Programa $A$ & Musical \\
\hline $11: 00$ às $12: 00$ & Programa $B-1^{\text {a }}$ Parte & Musical \\
\hline 12:00 às $13: 00$ & Histórias de Amor & Musical \\
\hline 13:00 às $15: 00$ & Programa $B-2^{\text {a }}$ Parte & Musical \\
\hline $15: 00$ às $18: 00$ & Seqüência Certa & Musical \\
\hline $18: 00$ às $19: 00$ & Disque Toque & Musical \\
\hline 20:00 às $22: 00$ & Programa $C$ & Musical \\
\hline 22:00 às $02: 00$ & Maringá by Night & Musical \\
\hline $02: 00$ às $07: 00$ & Madrugada & Musical \\
\hline
\end{tabular}

Quadro 4 - Rádio Maringá - FM 97,1 MHz

Fonte: emissora.

\begin{tabular}{|l|l|l|}
\hline 05:00 às 09:00 & Johnny Zanetti & Musical \\
\hline 09:00 às 13:00 & Araújo & Musical \\
\hline 13:00 às 17:00 & Claudiomar & Musical \\
\hline 17:00 às 22:00 & Souza Sobrinho & Musical \\
\hline 22:00 às 05:00 & Automatizado & Musical \\
\hline
\end{tabular}

Quadro 5 - Rádio Cultura - FM 102,5 MHz

Fonte: emissora.

Não seria exagero afirmar que a distinção entre as quatro emissoras (Antena 1, Joven Pan, Maringá FM e Cultura FM) se resume ao tipo de música que veiculam (direcionada, naturalmente, para pré-determinadas faixas do mercado). As sutilezas destas distinções não permitem, contudo, que duas, das três outras emissoras que transmitem em FM, se afastem muito do mencionado padrão. No caso da Rádio Novo Tempo, apesar de ligada à Igreja Adventista, a idéia de se "preencher" com música quase toda a programação e um "estilo" de locução e interação com o público muitas vezes semelhante à outras FM's, faz com que um ouvinte desatento chegue a pensar, em alguns momentos, que está ouvindo outra emissora. Usando freqüentemente um padrão de locução muito comum em outras emissoras FM (Maringá FM, Jovem Pan, etc) são utilizados quadros clássicos em que o ouvinte escolhe e dedica uma determinada música, promoções ou mesmo tradução de algum sucesso internacional. Contudo, diferentemente das emissoras "convencionais", a Rádio Novo Tempo ocupa um razoável tempo de sua programação com noticiários, entrevistas, e comentários (não necessariamente de natureza religiosa). Quanto à Rádio Universitária, sua semelhança com o "padrão" Antena 1 é talvez ainda mais curioso pelo fato de se tratar de uma emissora educativa, cujos conteúdos deveriam obedecer a um padrão regulamentado por legislação específica 
(a qual, salvo em caso de interpretação completamente "elástica", não permitiria definir como "conteúdos educativos" a quase exclusiva execução de músicas) ${ }^{15}$. Abaixo, suas respectivas grades de programação:

\begin{tabular}{|l|l|l|}
\hline 00:00 às 06:00 & Madrugada Viva & Religioso \\
\hline 06:00 às $08: 00$ & Bom Dia Novo Tempo & Religioso \\
\hline 08:00 às 12:00 & Programação Local & Religioso \\
\hline 12:00 às 13:00 & Conexão Novo Tempo & Religioso \\
\hline 13:00 às $18: 00$ & Revista Novo Tempo & Religioso \\
\hline 18:00 às 19:00 & Conexão Novo Tempo & Religioso \\
\hline 20:00 às $00: 00$ & Freqüência Novo Tempo & Religioso \\
\hline
\end{tabular}

Quadro 6 - Rádio Novo Tempo - FM 104,9 MHz

Fonte: emissora.

\begin{tabular}{|l|l|l|}
\hline 06:00 às $08: 00$ & Raízes Brasileiras & Musical \\
\hline 08:00 às $08: 30$ & O Mundo Hoje & BBC \\
\hline 08:30 às $11: 30$ & Manhã Popular Brasileira & Musical \\
\hline $11: 30$ às $12: 00$ & Universitária Notícias & Jornalismo \\
\hline $12: 00$ às $13: 00$ & Orquestras & Musical \\
\hline $13: 00$ às $17: 00$ & Sintonia Brasil & Musical \\
\hline $17: 00$ às $17: 30$ & O Mundo Hoje - II Edição & Jornalismo \\
\hline $17: 30$ às $19: 00$ & Casa de Bamba & Musical \\
\hline 20:00 às $21: 00$ & Músicos e Poetas & Musical \\
\hline $21: 00$ às $22: 00$ & Programas Especiais & Musical \\
\hline $22: 00$ às $23: 00$ & Música Erudita & Musical \\
\hline 23:00 às $00: 00$ & Jazz e Blues & Musical \\
\hline
\end{tabular}

Quadro 7 - Rádio Universitária - FM 106,9 MHz

Fonte: emissora.

Nesse sentido, tanto as quatro primeiras (Antena 1, Cultura FM, Jovem Pan e Maringá FM) quanto às duas últimas (Novo Tempo e Universitária) podem ser agrupadas dentro de um modelo que dedica a quase totalidade de seu tempo à execução de músicas

\footnotetext{
${ }^{15}$ A Portaria Interministerial no 651, assinada em 15 de abril de 1999, define os critérios de concessão para execução de serviços de radiodifusão exclusivamente educativa. Seus dois primeiros artigos estabelecem que (Art. $1^{\circ}$ ) "Por programas educativos-culturais entendem-se aqueles que, além de atuarem conjuntamente com os sistemas de ensino de qualquer nível ou modalidade, visem à educação básica ou superior, à educação permanente e formação para o trabalho, além de abranger as atividades de divulgação educacional, cultural, pedagógica e de orientação profissional, sempre de acordo com os objetivos nacionais", e que (Art. $2^{\circ}$ ) "Os programas de caráter recreativo, informativo ou de divulgação desportiva poderão ser considerados educativo-culturais, se neles estiverem presentes elementos instrutivos ou enfoques educativo-culturais identificados em sua apresentação".
} 
(praticamente só variando gêneros musicais e respectivas locuções).

Como única exceção entre as FM's, o modelo seguido pela Rádio CBN exclui totalmente a veiculação de música (a não ser pequenos trechos, quando a mesma se constitui parte de alguma reportagem) no corpo da programação. Esta, por sua vez, consiste na transmissão de notícias e programas de cunho jornalístico 24 horas por dia. Recentemente a emissora (que à semelhança das rádios Antena $1 \mathrm{e}$ Jovem Pan, opera em rede nacional) aumentou sua programação local para duas edições. Fortemente centrada no noticiário político e econômico, reproduz a mesma ênfase em sua versão local, deixando fora de seu rígido padrão jornalístico aquilo que ao mesmo não se adapte. Nesse particular, é mais uma vez interessante a comparação entre o "Programa Pinga Fogo" e "CBN Maringá" (quadro 2).

Se, do ponto de vista de boa parte da grande imprensa e das agências de publicidade, "ouvintes AM" (ou seja, classes C, D e E) são freqüentemente ignorados (por diversos fatores, sendo talvez o principal deles seu baixo poder aquisitivo, incapaz de atrair "bons anunciantes") no rádio quase ocorre o oposto. 0 rádio em geral (mas particularmente o rádio $\mathrm{AM}$ ) vem a se constituir num dos raros espaços da comunicação de massa no qual esse público, freqüentemente "retirado de cena" em outros meios, aparece, ainda que precariamente e muitas vezes caricaturado, dentro de perspectivas capazes de lhe reconhecer uma existência que é comumente negada em outros veículos. Já no caso da rádio CBN, apostando em faixas da população que não se imaginava capazes de "consumir rádio" (ou seja, classes A e B) seu projeto demonstrou ser possível, pela primeira vez em Maringá, a produção de um modelo de rádio comercial totalmente distinto dos demais, tradicional e comodamente assentados em esquemas que pouco ia além de música e hora certa.

\begin{tabular}{|l|l|l|l|}
\hline 06:30 às 09:30 & Jornal da CBN & Jornalismo & Heródoto Barbeiro \\
\hline 09:30 às 12:00 & CBN Maringá & Jornalismo & Marçal Siqueira \\
\hline 12:00 às 14:00 & CBN Brasil & Jornalismo & Carlos A. Sardenberg \\
\hline 14:00 às 16:00 & CBN Total & Jornalismo & Adalberto Piotto \\
\hline 16:00 às $17: 00$ & CBN Maringá - II Edição & Jornalismo & Marçal Siqueira \\
\hline $17: 00$ às $19: 00$ & Jornal da CBN - II Edição & Jornalismo & Roberto Nonato \\
\hline 20:00 às 21:00 & CBN Esporte Clube & Esportes & Juca Kfouri \\
\hline 21:00 às $00: 00$ & CBN Noite Total & Jornalismo & Roxane Ré \\
\hline 00:00 às 00:15 & CBN Madrugada & Jornalismo & Alves de Mello \\
\hline 00:15 às 01:15 & Programa do Jô & Entrevistas & Jô Soares \\
\hline 01:15 às 04:00 & CBN Madrugada & Jornalismo & Alves de Mello \\
\hline 04:00 às 06:00 & CBN Primeiras Notícias & Jornalismo & Reinaldo Bottino \\
\hline
\end{tabular}

Quadro 8 - Rádio CBN - FM 95,5 MHz

Fonte: site da emissora. 
As emissoras que operam em AM (Atalaia, Cultura, Difusora e Nova Ingá) dividem seus horários entre programas de forte apelo popular (onde predominam música sertaneja, horóscopo, noticiário policial, utilidade pública e assistencialismo) e espaços cedidos à terceiros (freqüentemente igrejas e seitas diversas). Além do mais que clássico Programa Pinga Fogo, anteriormente mencionado, outros "sucessos" do rádio AM maringaense se encontram fortemente consolidados na cidade, mantendo "receitas" certas para cada um de seus públicos. Entre os mais conhecidos podem ser mencionados: "Patrulha da cidade", com Rogério Rico (noticiário policial, com seu apresentador usando um estilo indignado e quase raivoso); "Programa Marquinhos Alves", (estilo sentimental, com música, mensagens de otimismo e brincadeiras com os ouvintes); "Programa Edson Lima" e "A voz do povo" (apresentados por Edson Lima e Paulo Mantovani respectivemente, giram em torno dos assuntos da política local, com abordagens nitidamente pessoais). Talvez o mais emblemático das tardes do rádio maringaense, o programa "Sertão na Cidade", apresentado por Maria Cristina, é descrito pela emissora como um

programa sertanejo classe A, que tem a comunicação simples da locutora Maria Cristina, que atende com carinho todos os ouvintes através de cartas e telefonemas. Além da boa música sertaneja apresentada neste programa, são apresentados também, vários quadros: simpatias, receitas de culinária, sexo do bebê, cantinho da correspondência, gente procurando gente e um especial de uma dupla sertaneja com uma bora de duração, etc.

Como questão óbvia que surge da análise da programação das emissoras de rádio, chama atenção a relação entre seus conteúdos e a legislação que deveria ordenar o setor. De acordo com as regras em vigor, o funcionamento das emissoras de rádio e TV encontrase condicionado a um processo que vai desde a concessão e permissão de funcionamento (dadas, respectivamente pelo presidente da República e pelo ministro das comunicações) até o cumprimento de determinadas condições e pré-requisitos específicos ${ }^{17}$. Entre esses, por exemplo, consta que as emissoras devem destinar pelo menos $5 \%$ de sua programação diária à transmissão de notícias, um mínimo de cinco horas semanais de programas educacionais e um máximo de 25\% de publicidade comercial em sua programação. Tais limites, bastante objetivos se comparados às orientações restantes que regulamentam 0 setor ("promover a cultura nacional e regional", "respeitar os valores éticos e sociais da

\footnotetext{
${ }^{17}$ A nova legislação, publicada em 26.12.96, altera ligeiramente o quadro atual, obrigando aqueles que forem exercer alguma função pública a se licenciarem de cargos na diretoria das emissoras. Também (teoricamente) desaparece o critério político na distribuição dos canais, passando o processo a ser feito por meio de licitação pública (ate 1996 cabia ao ministro das comunicações e ao presidente da República a decisão sobre quem receberia a concessão).
} 
pessoa e da família", etc) são freqüentemente contornados ou simplesmente descumpridos, não obstante terem seu funcionamento dependente do poder público, ao qual caberia fiscalizar o cumprimento do caráter social das empresas.

\begin{tabular}{|l|l|l|l|}
\hline 05:00 às 06:00 & Chora Viola & Musical & Braguito \\
\hline 06:00 às 08:00 & Hamilton Cardoso & Musical & Hamilton Cardoso \\
\hline 08:00 às 09:30 & Marquinhos Alves & Popular & Marquinhos Alves \\
\hline 09:30 às 10:00 & Opinião & Jornalismo & Humberto Crispim \\
\hline 10:00 às 11:00 & Tribuna do Povão & Jornalismo & Verdelírio Barbosa \\
\hline 11:00 às 12:00 & Falando de Jesus & Religioso & Miranda Leal \\
\hline 12:00 às 13:00 & Atalaia Esportiva & Esportes & Equipe Airton Costa \\
\hline 13:00 às 13:30 & O Brasil para Cristo & Religioso & O Brasil para Cristo \\
\hline 13:30 às 14:00 & Atalaia Negócios & Classificados & Ismael Mendonça \\
\hline 14:00 às 15:00 & Pastor Jacó & Religioso & Igreja Missionária Central \\
\hline 15:00 às 16:00 & Naldinho Alves & Popular & Naldinho Alves \\
\hline 16:00 às 19:00 & Momentos com Meu Deus & Religioso & Igreja Católica \\
\hline 20:00 às 21:00 & A Voz do Evangelho & Religioso & Pastor Valdemar Ribeiro \\
\hline 21:00 às 22:00 & Semeando a Palavra & Religioso & Presbítero Dalton Pereira \\
\hline 22:00 às 23:00 & Fonte do que Clama & Religioso & Ministério Varão de Fogo \\
\hline 23:00 às 24:00 & A Voz da Libertação & Religioso & Igreja Deus Amor \\
\hline
\end{tabular}

Quadro 9 - Rádio Atalaia - AM $1310 \mathrm{kHz}$

Fonte: emissora ${ }^{16}$

\begin{tabular}{|l|l|l|l|}
\hline 05:00 às 07:00 & Canta Meu Povo & Musical & João de Barro \\
\hline 07:00 às 07:30 & Jornal $1^{\text {a }}$ Hora & Em rede, com a Rádio Bandeirantes \\
\hline 07:30 às 10:00 & Programa Pinga Fogo & Jornalismo & Pinga Fogo \\
\hline 10:00 às 11:30 & Manhã Maior & Musical & Lúcio Correia \\
\hline 11:30 às $12: 30$ & Informativo & Jornalismo & R. Correia/Ari Bueno \\
\hline $12: 30$ às 13:30 & Pinga Fogo na TV & Jornalismo & Pinga Fogo \\
\hline 13:30 às 16:00 & Arquivo de Sucessos & Musical & Oliveirinha \\
\hline 16:00 às 18:00 & Canta Meu Povo & Musical & João de Barro \\
\hline 18:00 às 19:00 & Jornal da Bandeirantes & Em rede, com a Rádio Bandeirantes \\
\hline 20:00 às 22:00 & Sertanejo Classe A & Musical & Oliveirinha \\
\hline
\end{tabular}

Quadro 10 - Rádio Nova Ingá - AM 870 kHz

Fonte: emissora

\footnotetext{
${ }^{16}$ Os programas religiosos da emissora sofrem certa variação ao longo da semana, de modo que um determinado horário pode ser ocupado na segunda-feira por uma igreja, na terça por outra, na quarta por uma terceira, etc. 0 quadro 12, por esse motivo e sob forma de amostra, a programação de uma sexta-feira.
} 


\begin{tabular}{|l|l|l|l|}
\hline 05:00 às 07:30 & Show do Camilo & Musical & Roberto Camilo \\
\hline 07:30 às 10:00 & Programa Pinga Fogo & Jornalismo & Randhal Correia \\
\hline 10:00 às 11:30 & Bom Dia Mesmo & Horóscopo & Laudeci Aparecido \\
\hline 11:30 às $12: 30$ & Informativo Difusora & Jornalismo & R. Correia/Ari Bueno \\
\hline 12:30 às $13: 00$ & O Bom do Negócio & Classificados & Chico Maia \\
\hline 13:00 às $15: 00$ & Embalos da Tarde & Musical & Marcos Paulo \\
\hline 15:00 às 16:00 & Arquivo de Sucessos & Musical & Marcos Henrique \\
\hline 16:00 às 19:00 & Canta Meu Povo & Musical & Chico Maia \\
\hline 20:00 às 22:00 & Ouve Israel & Ouve Israel & Igreja Católica \\
\hline
\end{tabular}

Quadro 11 - Rádio Difusora - AM $960 \mathrm{kHz}$

Fonte: emissora

\begin{tabular}{|l|l|l|l|}
\hline 05:00 às 07:30 & Toledo Sertanejo & Musical & Antônio C. Toledo \\
\hline 07:30 às 08:00 & Momentos com Deus & Religioso & Igreja Só o Senhor é Deus \\
\hline 08:00 às 10:00 & Patrulha da Cidade & Policial & Rogério Rico \\
\hline 10:00 às 11:00 & Edson Lima & Jornalismo & Edson Lima \\
\hline 11:00 às 12:00 & A Voz do Povo & Jornalismo & Paulo Mantovani \\
\hline 12:00 às 13:00 & A Marcha do Esporte & Esportivo & Ananias Rodrigues \\
\hline 13:00 às 14:00 & Show da Tarde & Musical & Leonardo Silva \\
\hline 14:00 às 16:00 & Rádio Revista & Jornalismo & Ivo Cunha \\
\hline 16:00 às 19:00 & Sertão na Cidade & Variedades & Maria Cristina \\
\hline 20:00 às 22:00 & Sertão de Ouro & Musical & João Pereira \\
\hline 20:00 às 22:00 & A Voz da Libertação & Religioso & Igreja Deus é Amor \\
\hline
\end{tabular}

Quadro 12 - Rádio Cultura - AM $1390 \mathrm{kHz}$

Fonte: emissora

A questão do rádio no Brasil adquire contornos de grande interesse ao se considerar, por uma lado, o enorme potencial do veículo num país tão extenso, com altas taxas de analfabetismo e elevados índices de pobreza e, por outro lado, sua evidente sub-utilização. De acordo com a já citada Pesquisa Nacional por Amostra de Domicílios (PNAD) 91,9\% dos domicílios urbanos e 83,7\% dos domicílios rurais possuem rádio. Contudo, a existência de mais de 3.000 emissoras no país está longe de possuir um significado proporcional a esses números. A distribuição de centenas de concessões baseadas em critérios políticoseleitorais durante governos recentes só fez baixar ainda mais a qualidade das emissoras, ao mesmo tempo em que, por conta da conseqüente saturação do mercado, praticamente pulverizou a distribuição da verba publicitária entre as emissoras. Para que se tenha uma idéia aproximada do processo, dados coletados por Sônia Virgínia Moreira (1998, p. 94) informam que 
No total a administração Sarney distribuiu 1.028 concessões de emissoras de rádio (AM e FM) e de televisão - 30,9\% dos canais existentes na época. Em apenas um mandato José Sarney assinou um número de concessões superado pela soma das permissões autorizadas por todos os presidentes brasileiros entre 1934 e 1979: ao longo de 45 anos haviam sido outorgados 1.483 canais de rádio e TV, ou 44,5\% das emissoras que estavam no ar em 1989.

Ainda que, como já foi observado, parte da legislação que regula o setor seja explícita o suficiente para tirar do ar centenas de emissoras atualmente nas mãos de políticos e líderes de seitas religiosas, a fiscalização dos conteúdos, a cargo do Ministério das Comunicações, é praticamente inexistente, restando apenas a fiscalização técnica, de responsabilidade daANATEL (Agência Nacional de Telecomunicações). No que diz respeito às relações dos políticos com o rádio, uma pesquisa realizada em 1995 pelo jornal Folha de São Paulo sintetiza o quadro no país (LOBATO, 1995, p. 1/12):

É de praxe entre políticos adquirir meios de comunicação em nome de terceiros. 0 ex-governador de São Paulo, Orestes Quércia, possui duas TV's (Princesa D’Oeste, em Campinas, TV do Povo, em Santos) e uma rádio, em Sorocaba, que figuram em nome de outras pessoas no cadastro oficial. Oficialmente Quércia é titular de apenas três rádios: duas em Campinas e uma em São Paulo. [...] 'É muito difícil saber 0 número exato de deputados e senadores que possuem emissoras de rádio e TV', disse o deputado Jorge Maluly Netto (PFL/SP). Segundo ele, alguns são donos de fato, mas não aparecem porque se escondem atrás de testas-de-ferro (terceiros que assumem a responsabilidade em documentos públicos). Outros, segundo Maluly, aparecem no cadastro, mas não são donos de fato, porque emprestaram seus nomes para compor o quadro de acionistas das empresas como forma de obter a aprovação das concessões para seus aliados. 0 próprio Maluly aparece no cadastro do governo associado a uma emissora de TV e a cinco rádios (algumas em nome de sua mulher, Therezinha, e outras em nome do filho, Jorge).

No caso das igrejas e seitas, sua participação no rádio não é menos significativa. Um levantamento feito em 1997 pela mesma jornalista, (LOBAT0, 1997, p. 1/16) entre seitas e igrejas históricas, estabelece o número de emissoras ligadas à instituições religiosas:

\begin{tabular}{|l|c|}
\hline Igreja Católica & 181 \\
\hline Igreja Batista & 100 \\
\hline Igreja Universal do Reino de Deus & 70 \\
\hline Igreja Adventista do Sétimo Dia & 21 \\
\hline Igreja Assembléia de Deus & 12 \\
\hline Igreja Renascer em Cristo & 6 \\
\hline Igreja do Evangelho Quadrangular & 4 \\
\hline
\end{tabular}

Quadro 13 - Emissoras ligadas à instituições religiosas: 
Entre as rádios educativas, que somam 176 das mais de 3.000 estações em funcionamento, a situação não é muito melhor, ainda que por motivos diversos. A enorme maioria dessas emissoras encontra-se longe de apresentar, efetivamente, o caráter educativo que a legislação thes atribui. Ainda que a escassez de recursos contribua muito para isso (até certo ponto, considerando os relativamente baixos custos da produção radiofônica) as emisoras educativas parecem ter como modelo, paradoxalmente, as emissoras comerciais. Ao tentarem copiar e concorrer com esse modelo, mesmo que portando os diferenciais da "boa música" e dos "fins não lucrativos", as emissoras educativas não apenas se distanciam ainda mais da finalidade para a qual foram criadas como também terminam, pelo óbvio fato de não disporem de meios para levar adiante tal concorrência, por não serem também emissoras de entretenimento ou capazes de reter audiência significativa.

A situação do rádio em Maringá acaba por refletir, quase que fielmente e guardadas as devidas proporções, a situação acima descrita. Como de resto em todo o país, o quadro pouco animador do rádio no Brasil se daria em função da existência de enormes vazios: sistemático descumprimento da legislação que regulamenta o setor, freqüente desconhecimento das próprias características e possibilidades do veículo, e, de forma geral, de uma péssima utilização de um dos meios mais ricos e interessantes já inventados. E que, mais de cem anos após sua invenção, permanece contudo, em muitos lugares e através de inúmeras experiências, tão vivo, moderno e presente quanto as mais recentes experiências da cultura de massa.

"A quem isso vai servir?" "A todos que tiverem necessidade disso". 0 belo texto de Bachelard, em que sonho e rádio se confundem na solidão da noite, faz lembrar que, a despeito de seus produtores, donos e governos, as lembranças do rádio permanecem povoando a memória de seguidas gerações. Talvez mesmo por sua característica, quase romântica, de só praticamente exigir de seus ouvintes um pouco de imaginação. Contudo, ainda que os eternos lugares-comuns da imprensa lhe reservem um duvidoso espaço no passado ("a época de ouro do rádio", etc), o rádio parece estar melhor preparado para viver o futuro, onde 0 imediatismo, a sensorialidade e 0 rápido encontro entre as distâncias estarão talvez mais presentes que no momento.

Em tempos incomunicabilidade, em que as grandes corporações do setor e seus veículos assumem artificialmente o papel de falar, no lugar das pessoas, aquilo que as mesmas já calculam não valer mais a pena dizer umas às outras (e daí o fato de nunca a indústria do voyerismo e da vicariedade ter se desenvolvido com tanta intensidade), são poucos os espaços que parecem não significare confirmar esse esgotamento e essa distância. Talvez o rádio, ainda tão próximo da vida cotidiana e da quase rara sensação de existência de uma vida em comum, possa ajudar, um dia, a despertar esse desejo. 


\section{REFERÊNCIAS}

BACHELARD, Gaston. O direito de sonhar. São Paulo: Martins Fontes, 1986.

DEL BIANCO, Nélia; MOREIRA, Sônia Virgínia (Org.). Rádio no Brasil: tendências e perspectivas. Rio de Janeiro: EDUERJ/UNB, 1999.

FERRARETO, Luiz Artur. Rádio: o veículo, a história e a técnica. Porto Alegre: Sagra Luzzato, 2000 .

LOBAT0, Elvira. Igrejas têm quase 400 rádios. Folha de São Paulo, São Paulo, 10 ago. 1997.

LOBATO, Elvira. Um em cada seis congressistas tem rádio ou TV. Folha de São Paulo, São Paulo, 14 maio 1995.

MOREIRA, Sônia Virgínia. Rádio Palanque. Rio de Janeiro: Mil Palavras, 1998.

ORTRIWANO, Gisela Swetlana. A informação no rádio: os grupos de poder e a determinação dos conteúdos. São Paulo: Summus, 1985.

SCHÜTZ, Alfred. Dom Quixote e o problema da realidade. In: LIMA, Luiz Costa. Teoria da literatura e suas fontes. Rio de Janeiro: Francisco Alves, 1981. 